\title{
FOSFITO DE POTÁSSIO NA INDUÇÃO DE RESISTÊNCIA A Verticillium dahliae Kleb., EM MUDAS DE ÇACAUEIRO (Theobroma cacao L.)
}

\author{
Effect of potassium phosphite on the induction of resistance in cocoa \\ seedlings (Theobroma cacao L.) against Verticillium dahliae Kleb
}

\author{
Pedro Martins Ribeiro Júnior ${ }^{1}$, Mário Lúcio Vilela de Resende², Ricardo Borges Pereiraª \\ Fábio Rossi Cavalcanti ${ }^{4}$, Daniel Rufino Amaral ${ }^{5}$, Moisés Antônio de Pádua ${ }^{6}$
}

\begin{abstract}
RESUMO
Há vários relatos da utilização de fosfitos no controle de doenças de plantas, por meio de ação direta, antifúngica e indireta por indução de resistência. Essa atuação como indutor é questionada, não sendo encontradas, em muitos desses trabalhos, evidências de respostas de defesa ativadas pelos sais de fosfito. Com o presente trabalho, objetivou-se estudar o efeito de doses $\left(0,62 ; 1,25 ; 2,5\right.$ e $5 \mathrm{~mL} . \mathrm{L}^{-1}$ de água) de fosfito de potássio na indução de resistência em mudas de cacaueiro a $V$. dahliae, além de investigar os possíveis mecanismos envolvidos na resposta de defesa. Foram realizados experimentos no Laboratório de Fisiologia do Parasitismo e casa-de-vegetação do Departamento de Fitopatologia - UFLA. A aplicação foliar do fosfito foi realizada 7 dias antes das inoculações e as avaliações de severidade foram realizadas aos 20, 30, 40, 50 e 60 dias após a inoculação. Foi realizado também um experimento para verificar o efeito tóxico direto e outro para avaliar a atividade das enzimas peroxidases e polifenoloxidases e a concentração de lignina. $\mathrm{O}$ tratamento com o fosfito de potássio $\left(1,25 \mathrm{~mL} . \mathrm{L}^{-1}\right.$ de água) proporcionou 10\% de redução na área abaixo da curva de progresso da severidade da murcha-de-Verticillium (AACPD), 60 dias após aplicação foliar, não diferindo de nenhuma das doses, nem da testemunha. Todas as doses utilizadas apresentaram efeito fungitóxico, inibindo a germinação de $V$. dahliae. A aplicação do fosfito de potássio $\left(1,25 \mathrm{~mL} . \mathrm{L}^{-1}\right.$ de água) não induziu aumento na atividade das enzimas peroxidases e polifenoloxidases em relação à testemunha. Plantas tratadas com esse produto apresentaram um pequeno incremento na concentração de lignina, não apresentando diferença significativa da testemunha absoluta.
\end{abstract}

Termos para indexação: Theobroma cacao, murcha-de-Verticillium, lignina, peroxidases, polifenoloxidases.

\begin{abstract}
There are several reports concerning with the use of phosphites for controlling of plant diseases, through direct action, antifungal, and indirect, by resistance induction. The performance of phosphites as inducer of resistance is questioned, not finding in many of those papers, evidences of defense responses activated by these salts. The present work aimed at studying the effect of doses $\left(0.62 ; 1.25 ; 2.5\right.$ and $5.0 \mathrm{~mL} . \mathrm{L}^{-1}$ of water) of potassium phosphite on the protection of cocoa seedlings against $V$. dahliae, besides investigating the possible mechanisms involved in the defense response. Experiments were accomplished at the laboratory of Physiopathology and in a greenhouse at the Plant Pathology Department - UFLA. Foliar applications of phosphite were carried out 7 days before inoculation and severity assessments at 20,30, 40, 50 and 60 days after inoculation. Experiments were also set to verify the toxic effect of phosphites and to evaluate the action of the enzymes peroxidases and polyphenoloxidases and the lignin content. The treatment with the potassium phosphite (1.25 mL.L ${ }^{-1}$ of water) provided only $10 \%$ reduction in the area under the disease progress curve (AUDPC), 60 days after spraying, not differing from none of the doses, nor from the dose zero. All the used doses presented antifungal effect, inhibiting the germination of $V$. dahliae conidia. The application of the potassium phosphite $\left(1.25 \mathrm{~mL} . \mathrm{L}^{-1}\right.$ of water $)$ did not induce increase in the activities of the enzymes peroxidases and polyphenoloxidases in relation to the control. Treated plants with that product presented a small increment in the lignin content, not presenting a significant difference to the absolute control.
\end{abstract}

Index terms: Theobroma cacao, Verticillium wilt, lignin, peroxidases, polyphenoloxidases.

(Recebido para publicação em 9 de agosto de 2005 e aprovado em 6 de março 2006)

\footnotetext{
${ }^{1}$ Engenheiro Agrônomo, Doutorando do Departamento de Fitopatologia/DFP - Universidade Federal de Lavras/UFLA - Cx. P. 3037 - $37200-000$ Lavras, MG - ribeirojuniorpm@yahoo.com.br

${ }^{2}$ Ph.D. Professor Adjunto do Departamento de Fitopatologia/DFP - Universidade Federal de Lavras/UFLA - Cx. P. 3037 - $37200-000$ - Lavras, MG mlucio@ufla.br

${ }^{3}$ Engenheiro Agrônomo, Mestrando do Departamento de Fitopatologia/DFP - Universidade Federal de Lavras/UFLA - Cx. P. 3037 - $37200-000$ Lavras, MG - ricardoborges@yahoo.com.br

${ }^{4}$ Engenheiro Agrônomo, Doutorando do departamento de Fitopatologia/DFP - Universidade Federal de lavras/UFLA - Cx. P. 3037 - $37200-000$ Lavras, MG - rossi217@yahoo.com.br

${ }^{5}$ Engenheiro Agrônomo, Doutorando do Departamento de Fitopatologia/DFP — Universidade Federal de Lavras/UFLA - Cx. P. 3037 - $37200-000$ Lavras, MG - dandanruf@yahoo.com.br

${ }^{6}$ Biólogo, Bolsista CNPq - Departamento de Fitopatologia/DFP - Universidade Federal de Lavras/UFLA - Cx. P. 3037 - $37200-000$ - Lavras, MG.
} 


\section{INTRODUÇÃO}

Verticillium dahliae Kleb. é um fungo habitante do solo que causa murcha vascular em várias espécies de plantas cultivadas (RESENDE, 1994). Em cacaueiro (Theobroma cacao L.), este patógeno representa um fator limitante à produção em algumas das principais regiões produtoras do mundo, principalmente em condições de deficiência hídrica, com períodos prolongados de seca (ALMEIDA et al., 1993). A murcha-de-Verticillium pode induzir sintomas foliares (epinastia, murcha, descoloração e desfolha), vasculares (descoloração do xilema e entupimento de vasos) e declínio (definhamento e morte) (HIEMSTRA, 1998).

O manejo da murcha-de-Verticillium em espécies arbóreas é difícil, pois o fungo produz microescleródios, estruturas de resistência que podem sobreviver no solo por vários anos. De maneira geral, devem ser tomados alguns cuidados, como plantio em área livre do patógeno, desinfestação do solo com fumigantes, solarização, adubos verdes ou controle biológico, uso de material livre do patógeno, uso de cultivares resistentes e minimização de práticas culturais que danifiquem as raízes (GOUD, 2003).

As limitações existentes à aplicação de defensivos agrícolas na cultura do cacaueiro aliados à escassez de cultivares com elevado nível de resistência, fazem com que a resistência induzida represente uma alternativa potencial no combate às principais doenças nessa cultura.

Um produto utilizado no manejo de doenças de plantas, inclusive em espécies arbóreas é o fosfito de potássio, sendo indicado no controle de oomycetos como Phytium spp. e Phytophthora spp. e de fungos causadores de podridões do colo, raiz, tronco e frutos (MCDONALD et al., 2001). O efeito direto do fosfito no metabolismo de Phytophthora é importante na supressão da doença, contudo, este não deve ser o único mecanismo de ação do produto no controle do patógeno que, na realidade, resultaria de uma ação mista envolvendo também a ativação do sistema de defesa natural da planta (SMILLIE et al., 1989).

Os sais de fosfito também estão sendo usados com sucesso em doenças causadas por outros fungos como míldio em crucíferas, de maneira dependente da dose utilizada. A proteção restringiu-se apenas aos tecidos tratados, não havendo resposta sistêmica, embora os autores sugiram a atuação sinergística dos modos de ação direto sobre o patógeno e indireto, ativando as defesas dessas hortaliças (BÉCOT et al., 2000). Frutos de macieira tratados com fosfito de potássio $(250 \mathrm{~mL} / 100 \mathrm{~L})+\mathrm{CaCl}_{2}$ (2\%) apresentaram menor incidência de podridões e menor diâmetro de lesões. Esses resultados foram semelhantes aos obtidos com a aplicação do fungicida padrão iprodione e superiores à aplicação de fosfito de potássio isoladamente (BRACKMANN et al., 2004).

De maneira geral, com o presente trabalho, objetivou-se estudar o efeito do fosfito de potássio como indutor de resistência no cacaueiro a $V$. dahliae e estudar os mecanismos envolvidos na resposta de defesa como peroxidases, polifenoloxidases e lignina.

\section{MATERIAL E MÉTODOS}

Os experimentos foram conduzidos no Laboratório de Fisiologia do Parasitismo e em casa-de-vegetação do Departamento de Fitopatologia da Universidade Federal de Lavras-MG.

\section{Efeito direto de doses de fosfito de potássio na germinação de conídios de $V$. dahliae}

Para se verificar a toxidez direta das doses de fosfito de potássio a $V$. dahliae foram realizados testes de germinação em lâminas escavadas com três cavidades, utilizando-se um isolado de $V$. dahliae de quiabeiro (Abelmoschus esculentus Moench.), oriundo do município de Lavras, MG. Em cada cavidade foi depositada $40 \mu \mathrm{L}$ da suspensão de conídios $\left(10^{6}\right.$ conídios. $\left.\mathrm{mL}^{-1}\right)$ e $40 \mu \mathrm{L}$ dos produtos: fosfito de potássio (Hortifos ${ }_{\mathrm{PK}}{ }^{\circledR}-27 \% \mathrm{de}_{2} \mathrm{P}_{2} \mathrm{O}_{5} \mathrm{e}$ $27 \%$ de $\mathrm{K}_{2} \mathrm{O}$, da Agrichem do Brasil Ltda) 0,62; 1,25; 2,5 e $5 \mathrm{~mL} . \mathrm{L}^{-1}$ de água; acibenzolar-S-metil (ASM, 0,2 g.L $\mathrm{L}^{-1}$ ) e no tratamento testemunha foram adicionados $40 \mu \mathrm{L}$ de água destilada esterilizada. As lâminas foram incubadas em ambiente saturado e mantidas a $25^{\circ} \mathrm{C}$, sob regime de 12 horas de luz e 12 horas de escuro, por um período de 24 horas. Após este período, foi paralisado o crescimento do fungo por meio da adição de 10iL de solução de lactoglicerol em cada cavidade. $\mathrm{O}$ delineamento experimental foi o inteiramente ao acaso, com seis repetições e os dados foram analisados utilizando-se $o$ programa SISVAR $^{\circledast}$ (FERREIRA, 2000).

Efeito de doses de fosfito de potássio na severidade da murcha-de-Verticillium em mudas de cacaueiro

Nos experimentos foram utilizadas plântulas obtidas a partir de sementes de cacaueiro da cultivar "EEG 64", suscetível à murcha-de-Verticillium, provenientes da Ceplac - Linhares, ES. As sementes foram pré-germinadas em bandejas contendo substrato vermiculita e, após 7 dias, transplantadas para sacos de 3 litros contendo o substrato composto por terra, areia e esterco bovino na proporção de 2:1:1, respectivamente. As mesmas foram dispostas em bancadas de aço e mantidas em casa-de-vegetação com temperatura em torno de $25^{\circ} \mathrm{C}$. 
Foi realizada pulverização foliar com fosfito de potássio em quatro doses: 0,$62 ; 1,25 ; 2,5$ e $5 \mathrm{~mL} . \mathrm{L}^{-1}$ de água seguidas por inoculação com $V$. dahliae, sete dias após. Foi utilizada também uma testemunha sem inoculação, além de outra inoculada (dose 0) e um tratamento com o ASM, acibenzolar-S-metil, (0,2g. $\mathrm{L}^{-1}$ de água) seguido por inoculação.

A inoculação foi realizada de acordo com a metodologia de Bugbee \& Presley (1967) pelo método de punção caulinar, utilizando-se seringas e agulhas estéreis. A agulha foi inserida em um ângulo de $45^{\circ}$ com o eixo do caule até atingir o lenho da planta, sendo depositada uma gota de suspensão de conídios $\left(10^{6}\right.$ conídios. $\left.\mathrm{mL}^{-1}\right)$. As plantas testemunhas foram tratadas, de maneira similar, com uma gota de água estéril.

As avaliações da severidade da doença foram realizadas aos 20, 30, 40, 50 e 60 dias após a inoculação, utilizando-se uma escala de notas preconizada por Sidhu $\&$ Webster (1977), com notas variando de 0 a 4 , em que $0=$ ausência de sintomas, $1=1 \%$ a $25 \%, 2=26 \%$ a $50 \%, 3=$ $51 \%$ a $75 \%$ e $4=$ mais de $75 \%$ de redução da área foliar devido a clorose, necrose e murcha.

Para ponderar a severidade na planta, foi aplicado o índice de McKinney (1923) e a área abaixo da curva de progresso da murcha-de-Verticillium (AACPD) foi obtida com base nos índices de severidade, de acordo com Campbell \& Madden (1990).

O delineamento experimental utilizado foi de blocos casualizados, com três repetições e 12 plantas por parcela e os dados foram analisados utilizando-se o programa SISVAR $^{\circledR}$ (FERREIRA, 2000).

\section{Determinação dos mecanismos bio químicos envolvidos na resposta de defesa}

Para a determinação dos mecanismos envolvidos na resposta de defesa, utilizando-se a dose que proporcionou menor AACPD no experimento anterior, foram utilizadas plântulas de cacaueiro cultivar "EEG 64", com aproximadamente quatro folhas, cultivadas sem estresse em bandejas contendo substrato Plantmax ${ }^{\grave{O}} \mathrm{e}$ irrigadas diariamente com solução nutritiva de Hoagland \& Arnon (1950).

$\mathrm{O}$ experimento consistiu de seis tratamentos: dose que apresentou menor AACPD do experimento com as mudas, ASM (0,2 g. $\mathrm{L}^{-1}$ de água) e um tratamento com água, todos seguidos por inoculação ou não com $V$. dahliae (BUGBEE \& PRESLEY, 1967). Os tratamentos foram aplicados quatro dias antes da inoculação e as coletas foram realizadas aos 4, 8, 13 e 18 dias após a pulverização. O delineamento experimental utilizado foi o de blocos casualizados, com três repetições e parcela experimental composta de duas plantas por coleta.

Para a determinação das proteínas totais, peroxidases e polifenoloxidases foi utilizado $1,5 \mathrm{~g}$ de caule, coletados no local da inoculação, macerados em almofariz com tampão acetato de sódio $50 \mathrm{mM}, \mathrm{pH} 5,2$, contendo $\mathrm{NaCl}$ 0,5 M e 0,4\% de ácido cítrico. Posteriormente, a mistura foi filtrada em gaze dobrada e a suspensão foi centrifugada a $4^{\circ} \mathrm{C}(14.000 \mathrm{~g}$ por 15 minutos). $\mathrm{O}$ sobrenadante foi mantido a $-20^{\circ} \mathrm{C}$, até o momento das análises.

A determinação das concentrações de proteínas solúveis totais foi realizada de acordo com o método proposto por Bradford (1976), a determinação da atividade de peroxidases e polifenoloxidases foi realizada de acordo com a metodologia de Kar \& Mishra (1976) e os resultados foram expressos em unidade de atividade por miligrama de proteína por minuto.

O conteúdo de lignina foi determinado como descrito por Stadnik (1999), por meio do ensaio com ácido tioglicólico (MONTIES, 1989) e os resultados expressos em micrograma de lignina por miligrama de matéria fresca.

\section{RESULTADOS E DISCUSSÃO}

\section{Efeito de doses de fosfito de potássio na germinação de conídios de $V$. dahliae}

Todas as doses de fosfito de potássio testadas apresentaram algum efeito tóxico na germinação de conídios de $V$. dahliae. Nas doses de 2,5 e 5,0 mL.L $\mathrm{L}^{-1}$ a germinação dos conídios foi de $0 \%$ e $1 \%$, enquanto que nas doses de 0,62 e $1,25 \mathrm{~mL} . \mathrm{L}^{-1}$ foi de $35 \%$ e $21 \%$, respectivamente. (Tabela 1). No tratamento com o ASM $\left(0,2\right.$ g. $\left.^{-1} \mathrm{~L}\right)$ a germinação foi de $67 \%$. Aparentemente, os conídios germinados tratados com fosfito de potássio apresentaram tubos germinativos menores que os tratados com ASM e a testemunha. Nojosa (2003), trabalhando com Phoma costarricensis em cafeeiro, observou que o fosfito de potássio na dose $10 \mathrm{~mL} . \mathrm{L}^{-1}$ inibiu o crescimento micelial em $62 \%$ e nas doses de 1,5 a $10 \mathrm{~mL} . \mathrm{L}^{-1}$ reduziu o comprimento do tubo germinativo em $32,6 \%$, enquanto que o fosetil-Al inibiu $100 \%$ do crescimento micelial nas doses de 2 a 4 g.L. $\mathrm{L}^{-1}$. De acordo com Feen \& Coffey (1989), o efeito do fosfito de potássio seria tão potente quanto o do fosetil-Al, pois possui modo de ação similar ao mesmo. 
Efeito de doses de fosfito de potássio na severidade da murcha-de-Verticillium em mudas de cacaueiro

Não houve efeito significativo das doses de fosfito de potássio testadas, entretanto a dose que apresentou menor AACPD em relação à testemunha inoculada foi 1,25 mL.L ${ }^{-1}$, com $10 \%$ de redução na AACPD (Figura 1), entretanto não diferiu estatisticamente das demais doses. $\mathrm{O}$ tratamento com ASM apresentou menor AACPD que as doses de fosfito de potássio (teste de Scott-Knott, p d" 0,05), tendo conferido proteção de $30 \%$ em relação à testemunha inoculada.

Vários trabalhos relatam a eficácia de fosfitos em reduzir doenças em plantas, principalmente doenças causadas por oomycetos (FOSTER et al., 1998). Entretanto, não há relatos para doenças vasculares, provavelmente porque resultados negativos não têm sido divulgados.

TABELA 1 - Efeito de doses de fosfito de potássio e do ASM (acibenzolar-S-metil) na germinação de conídios de Verticillium dahliae.

\begin{tabular}{lc}
\hline \multicolumn{1}{c}{ Tratamento } & Germinação média (\%) \\
\hline Testemunha & 100 \\
Fosfito de potássio $0,62 \mathrm{~mL} \cdot \mathrm{L}^{-1}$ & 35 \\
Fosfito de potássio $1,25 \mathrm{~mL} . \mathrm{L}^{-1}$ & 21 \\
Fosfito de potássio $2,5 \mathrm{~mL} . \mathrm{L}^{-1}$ & 1 \\
Fosfito de potássio $5 \mathrm{~mL} . \mathrm{L}^{-1}$ & 0 \\
ASM $0,2 \mathrm{~g} . \mathrm{L}^{-1}$ & 67 \\
\hline
\end{tabular}

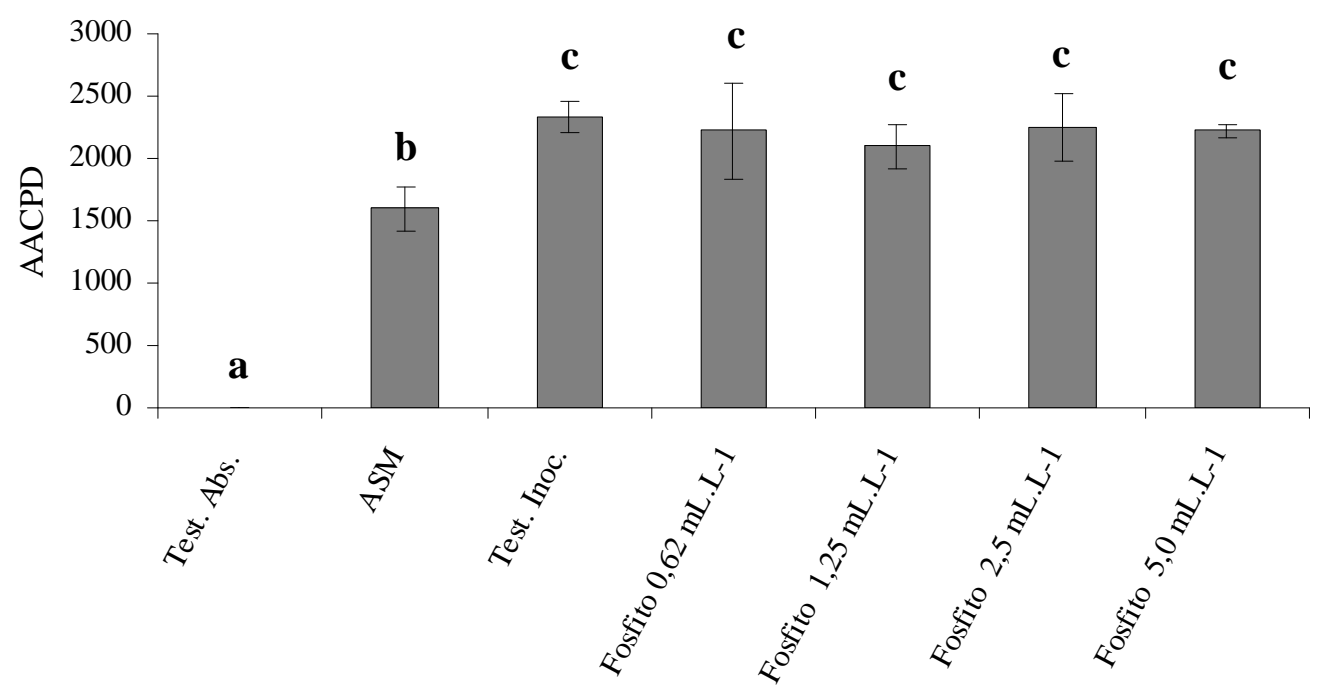

Tratamentos

FIGURA 1 - Área abaixo da curva de progresso da severidade da murcha-de-Verticillium (AACPD) em mudas de cacaueiro. Tratamentos: ASM: acibenzolar-S-metil seguido por inoculação; Fosfito: fosfito de potássio nas respectivas dosagens seguidos por inoculação; Test. Abs.: testemunha absoluta; Test. Inoc.: testemunha inoculada.. Barras = desvio padrão da média. Médias com mesma letra não diferem entre si pelo teste de Scott-Knott (P d” 0,05$)$.

Ciênc. agrotec., Lavras, v. 30, n. 4, p. 629-636, jul./ago., 2006 
Efeito do fosfito de potássio na atividade de peroxidases, polifenoloxidases e na lignificação

Caules de plantas tratadas com o ASM, adotado como padrão de indução de resistência, e inoculados com o patógeno apresentou pico de peroxidases, 13 dias após pulverização, aumentando ainda mais aos 18 dias, enquanto que plantas tratadas com o ASM, sem inoculação, apresentaram uma maior atividade dessa enzima aos 18 dias após pulverização (Figura 2 A).

Foi observado um pequeno incremento na atividade da peroxidases aos 13 dias após a pulverização do fosfito de potássio $\left(1,25 \mathrm{~mL} . \mathrm{L}^{-1}\right)$ seguido por inoculação com $V$. dahliae, fato também observado na testemunha inoculada. Esse comportamento demonstra que a inoculação por meio de punção caulinar também promoveu um aumento suave na atividade de peroxidases podendo ser uma resposta da planta ao ferimento (Figura $2 \mathrm{~B}$ ).

O tratamento com ASM (0,2 g. $\left.\mathrm{L}^{-1}\right)$ seguido por inoculação induziu um aumento na atividade de polifenoloxidases aos 18 dias após pulverização. De acordo com a Figura 3A, ocorreu uma tendência de aumento de polifenoloxidases na testemunha inoculada e no tratamento com ASM sem inoculação aos 18 dias após pulverização. Não foi observada mudança na atividade de polifenoloxidases na testemunha não inoculada com $V$. dahliae, nem na testemunha inoculada com água. A aplicação de fosfito de potássio $\left(1,25 \mathrm{~mL} . \mathrm{L}^{-1}\right)$ não induziu incremento significativo na atividade de polifenoloxidases (Figura 3B).

Paredes lignificadas podem impedir a penetração ou desenvolvimento de fungos em tecidos vegetais (AGRIOS, 1997; PASCHOLATI \& LEITE, 1995). Em cafeeiro, Nojosa (2003), observou uma maior lignificação em plantas de cafeeiro tratadas com fosfito de potássio (5 mL. $\mathrm{L}^{-1}$ ), sem inoculação e inoculadas com Hemileia vastatrix. Entretanto, em mudas de cacaueiro o tratamento com fosfito de potássio $\left(1,25 \mathrm{~mL} . \mathrm{L}^{-1}\right)$ não aumentou o conteúdo de lignina, não diferindo estatisticamente dos demais tratamentos, incluindo o ASM (Figura 4).
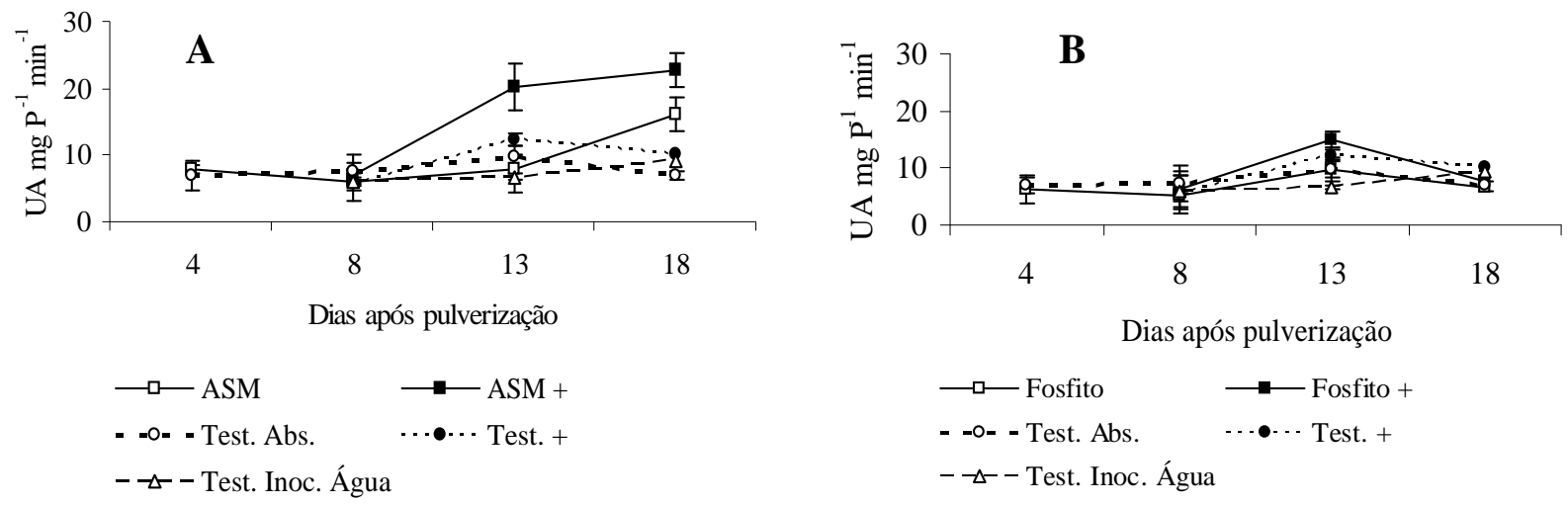

FIGURA 2 - Efeito do ASM e fosfito de potássio sobre a atividade de peroxidases em caules de mudas de cacau. UA.mgP ${ }^{-1} \cdot \min ^{-1}$ : unidade de atividade por miligrama de proteína por minuto. Tratamentos: ASM: acibenzolar-S-metil; ASM+: acibenzolar-S-metil seguido por inoculação; Fosfito: fosfito de potássio (1,25 mL.L $\left.{ }^{-1}\right)$; Fosfito +: fosfito de potássio (1,25 mL.L-1 $)$ + inoculação; Test. Abs.: testemunha absoluta; Test +: testemunha + inoculação; Test. Inoc. Água: testemunha inoculada com água. A inoculação foi realizada aos cinco dias após a pulverização dos tratamentos. Barras = desvio padrão da média. 


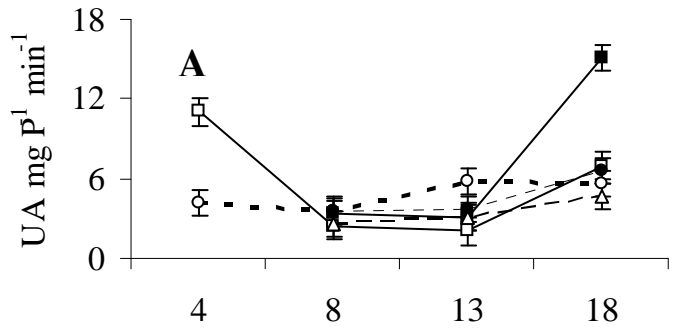

Dias após pulverização

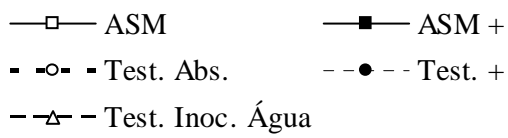

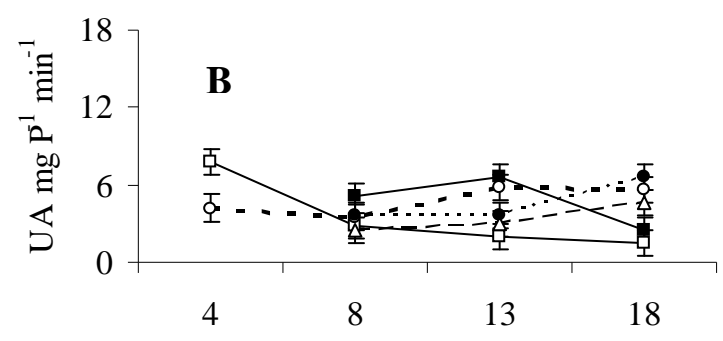

Dias após pulverização

$$
\begin{aligned}
& \longrightarrow \square-\text { Fosfito } \\
& --\circ-- \text { Test. Abs. } \\
& -\triangle-- \text { Test. Inoc. Água }
\end{aligned}
$$

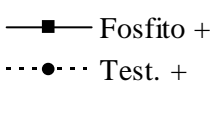

FIGURA 3 - Efeito do ASM e fosfito de potássio sobre a atıvıdade de polıtenoloxıdases em caules de mudas de cacau. UA.mgP ${ }^{-1} \cdot \min ^{-1}$ : unidade de atividade por miligrama de proteína por minuto. Tratamentos: ASM: acibenzolar-S-metil; ASM+: acibenzolar-S-metil seguido por inoculação; Fosfito: fosfito de potássio (1,25 mL.L $\left.{ }^{-1}\right)$; Fosfito +: fosfito de potássio (1,25 mL.L-1 $)$ + inoculação; Test. Abs.: testemunha absoluta; Test +: testemunha + inoculação; Test. Inoc. Água: testemunha inoculada com água. A inoculação foi realizada aos cinco dias após a pulverização dos tratamentos. Barras $=$ desvio padrão da média.

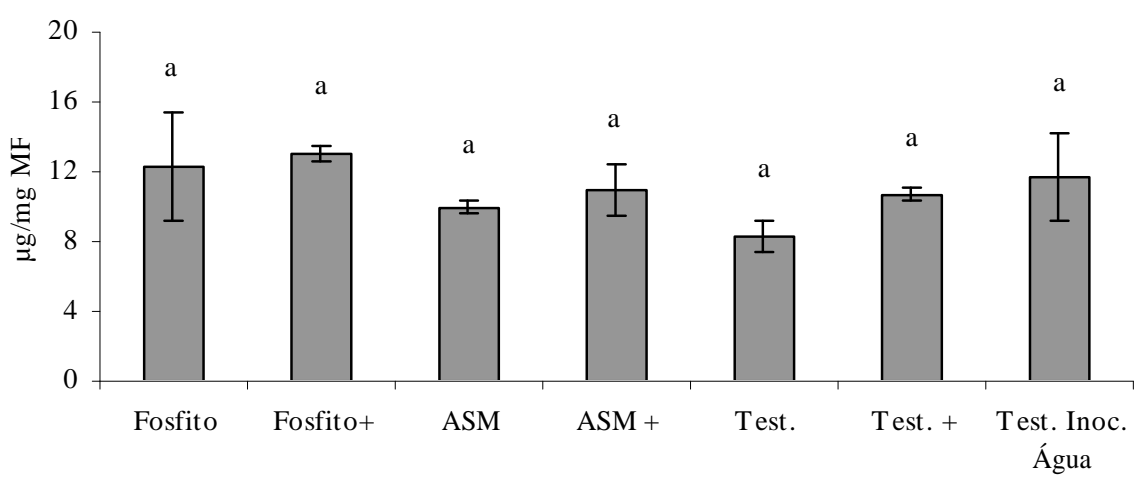

Tratamentos

FIGURA 4 - Concentração de lignina ácido solúvel em caule de plântulas de cacaueiro cultivar "EEG 64" aos 18 dias após pulverização com os tratamentos: ASM: acibenzolar-S-metil; ASM+: acibenzolar-S-metil seguido por inoculação; Fosfito: fosfito de potássio $\left(1,25 \mathrm{~mL} . \mathrm{L}^{-1}\right)$; Fosfito +: fosfito de potássio $\left(1,25 \mathrm{~mL} . \mathrm{L}^{-1}\right)+$ inoculação; Test. Abs.: testemunha absoluta; Test +: testemunha + inoculação; Test. Inoc. Água: testemunha inoculada com água. A inoculação foi realizada aos cinco dias após a pulverização dos tratamentos. Barras = desvio padrão da média. Médias com mesma letra não diferem pelo teste de Scott-Knott (p d" 0,05).

\section{CONCLUSÕES}

O fosfito de potássio em todas as doses utilizadas, 0,62, 1,25, 2,5 e $5 \mathrm{~mL} . \mathrm{L}^{-1}$ de água, apresentou efeito fungitóxico, inibindo a germinação de conídios de $V$. dahliae.

O fosfito de potássio, nas dosagens utilizadas, não teve efeito protetor significativo em mudas de cacaueiro contra $V$. dahliae.

Fosfito de potássio $\left(1,25 \mathrm{~mL} \cdot \mathrm{L}^{-1}\right)$ não induziu, em cacaueiro, aumento significativo na atividade das enzimas peroxidases e polifenoloxidases, nem promoveu incremento no conteúdo de lignina. 


\section{REFERÊNCIAS BIBLIOGRÁFICAS}

AGRIOS, G. N. Plant pathology. 4. ed. San Diego: Academic, 1997.

ALMEIDA, H. A.; ALMEIDA, L. C.; LIMA, A. A. Efeito da deficiência hídrica sobre a murcha-de-Verticillium no cacaueiro. In: CONGRESSO BRASILEIRO DE AGROMETEOROLOGIA, 8., 1993, Santa Maria, RS. Anais... Santa Maria: [s.n.], 1993. p. 187.

BÉCOT, S.; PAJOT, E.; LE CORRE, D.; MONOT, C.; SILUÉ, D. Phytogard $\left(\mathrm{K}_{2} \mathrm{HPO}_{3}\right)$ induces localized resistance in cauliflower to downy mildew of crucifers. Crop Protection, Surrey, v. 19, p. 417-425, 2000.

BRACKMAN, A.; GIEHL, R. F. H.; SESTARI, I.; STEFFENS, C. A. Fosfitos para o controle de podridões pós-colheita em maçãs 'Fuji' durante o armazenamento refrigerado. Ciência Rural, Santa Maria, v. 34, n. 4, p. 10391042, 2004.

BRADFORD, M. M. A rapid and sensitive method for the quantitation of microgram quantities of protein utilizing the principle of protein-dye binding. Analitical Biochemistry, San Diego, v. 72, n. 1/2, p. 248-254, 1976.

BUGBEE, W. M.; PRESLEY, T. J. A rapid inoculation tecnique to avaluate the resistance of cotton to Verticillium albo-atrum. Phytopathology, Saint Paul, v. 57, n. 11, p. 1264, Nov. 1967.

CAMPBELL, C. L.; MADDEN, L. V. Introduction to plant disease epidemiology. New York: J. Wiley, 1990. 532 p.

FENN, M. E.; COFFEY, M. D. Quantification of phosphonate and ethyl phosphate in tobacco and tomato tissues and significance for the mode of action of two phosphonate fungicides. Phytopathology, Saint Paul, v. 79, n. 1, p. 76-82, Jan. 1989.

FERREIRA, D. F. Análises estatísticas por meio do SISVAR para Windows versão 4.0. In: REUNIÃO ANUAL DA REGIÃO BRASILEIRA DA SOCIEDADE INTERNACIONAL DE BIOMETRIA, 45., 2000, São Carlos, SP. Programas e Resumos... São Carlos: UFSCar, 2000. p. 235.

FOSTER, H.; ADASCAVEG, J. E.; KIM, D. H.; STHANGELLINE, M. E. Effect of phosphite on tomato and pepper plants and on susceptibility of pepper to phytophthora root and crown rot in hydroponic culture. Plant Disease, Quebec, v. 82, n. 10, p. 1165$1171,1998$.

GOUD, J. C. Verticillium wilt in trees: detection, prediction and disease management. 2003. 98 f. Thesis (Ph.D) Wageningen Universiteit, Wageningen, 2003.

HIEMSTRA, J. A. Some general features of verticillium wilts in trees. In: HIEMSTRA, J. A.; HARRIS, D. C. (Eds.). A compendium of verticillium wilts in tree species. Wageningen: CPRO-DLO/HRI-EM, 1998. p. 5-11.

HOAGLAND, R.; ARNON, I. The water culture method for growing plants without soil. Circular of the California Agricultural Experiment Station, Miami, n. 347, p. 1-32, 1950 .

KAR, M. E.; MISHRA, D. Catalase, peroxidase and polyphenoloxidase activities during rice leaf senescence. Plant Physiology, Rockville, v. 57, n. 2, p. 315-319, Feb. 1976.

McDONALD, A. E.; GRANT, B. R.; PLAXTON, W. C. Phosphite (phosphorous acid): its relevance in the environment and agriculture and influence on plant phosphate starvation response. Journal of Plant Nutrition, New York, v. 24, n. 10, p. 1505-1519, 2001.

McKINNEY, H. H. Influence of soil temperature and moisture on infection of wheat seedlings by Helmintosporium sativum. Journal agricultural Research, Washington, v. 26, n. 5, p. 195-219, Nov. 1923.

MONTIES, B. Lignins. In: DEY, P. M.; HARBORNE, J. B. (Eds.). Methods in plant biochemistry. New York: Academic, 1989. p. 113-158.

NOJOSA, G. B. A. Efeito de indutores na resistência de Coffea arabica L. à Hemileia vastatrix BERK \& BR. e Phoma costarricensis ECHANDI. 2003. 102 p. Tese (Doutorado em Fitopatologia) - Universidade Federal de Lavras, Lavras, 2003.

PASCHOLATI, S. F.; LEITE, B. Hospedeiro: mecanismos de resistência. In: BERGAMIN FILHO, A.; KIMATI, H.; AMORIM, L. (Eds.). Manual de fitopatologia: principíos e conceitos. São Paulo: Agronômica Ceres, 1995. v. 1, cap. 22, p. 417-454. 
RESENDE, M. L. V. Vascular wilt of cocoa (Theobroma cacao L.), caused by Verticillium dahliae Kleb.: studies on patogenicity and resistance. 1994. Thesis (Ph.D) University of Bath, Bath, 1994.

SIDHU, G. S.; WEBSTER, J. M. The use of aminoacid fungal auxotrophs to study the predisposition phenomena in the root-knot: wilt fungus disease complex. Physiological Plant Plathology, London, v. 11, n. 2, p. 117-127, 1977.
SMILLIE, R.; GRANT, B. R.; GUEST, D. The mode of action of phosphite: evidence for both direct and indirect modes of action on three Phytophthora spp in plants. Phytopathology, Saint Paul, v. 79, n. 9, p. 921-926, Sept. 1989.

STADNIK, M. J. Induction of resistance in wheat by a benzothiadiazole derivative against the powdery mildew (Blumeria graminis f. sp. tritici): practical aspects and mechanisms of action. 1999. Thesis (Ph.D) - University of Hohenheim, Stuttgart, 1999.

Ciênc. agrotec., Lavras, v. 30, n. 4, p. 629-636, jul./ago., 2006 